\title{
Lollipop Dosing Unit
}

National Cancer Institute

\section{Source}

National Cancer Institute. Lollipop Dosing Unit. NCI Thesaurus. Code C122633.

A dosing unit equal to the amount of active ingredient(s) contained in a lollipop. 